\title{
Expression of p16 and p53 in Intraepithelial Periocular Sebaceous Carcinoma
}

\author{
W. Robert Bell Kamaljeet Singh Anand Rajan KD Charles G. Eberhart
}

The Johns Hopkins University School of Medicine, Baltimore, Md., USA

\section{Key Words}

Sebaceous carcinoma $\cdot$ p16 immunohistochemistry $\cdot$ p53

immunohistochemistry · Intraepithelial spread

\begin{abstract}
Purpose: Identifying intraepithelial sebaceous carcinoma cells in small periocular biopsies can be difficult, particularly in the conjunctiva. The goal of this study was to evaluate p53 and p16 immunohistochemistry as potential markers of intraepithelial sebaceous carcinoma. Procedures: A total of 25 tumors, including 4 recurrent lesions, were stained for $\mathrm{p} 16$ and $\mathrm{p} 53$, with intensity scored as negative, weak, moderate or strong. Results: Expression of p16 was detected in intraepithelial sebaceous carcinoma cells in 24 of the 25 cases (96\%), with only 1 case showing weak immunoreactivity. Intraepithelial p53 immunoreactivity was present in 17 of 25 tumors (68\%), but was weak in 3 cases. Expression levels remained relatively stable in primary and recurrent tumors, but varied in a few cases between intraepithelial and subepithelial sites. Conclusions: Intraepithelial sebaceous carcinomas stained for $\mathrm{p} 53$ and $\mathrm{p} 16$ demonstrated moderate to strong immunoreactivity in $100 \%$ of cases for at least one of these proteins, suggesting that together they are useful markers for determining the extent of tumor spread. Of the two, p16 was immunoreactive in more cases than p53.
\end{abstract}

(c) 2015 S. Karger AG, Basel

\section{Introduction}

Sebaceous carcinoma (SC) accounts for $1.3-4.7 \%$ of malignant eyelid tumors in the United States [1-3]. Clinical diagnosis can be challenging due to its ability to mimic other common processes including chalazion and blepharitis. In addition to forming subepithelial masses in the lid, these tumors often exhibit intraepithelial spread in the skin or conjunctiva, with isolated cells extending far from the main tumor, sometimes with only minimal disruption of the epithelial architecture. Determining the extent of intraepithelial spread can be difficult, particularly in mapping biopsies or at the margins of larger resections. The goal of this study was to evaluate p53 and p16 as potential immunohistochemical markers of periocular SC by examining their expression in both subepithelial and intraepithelial tumors.

\section{Methods}

Specimens were retrieved from the Surgical Pathology and Ophthalmic Pathology Archives of The Johns Hopkins Hospital, Baltimore, Md., USA. Representative SC cases were obtained from 21 patients operated on from 1985 to 2012, including 4 patients with both original and recurrent tumor. Three consecutive conjunctival intraepithelial neoplasia cases from 2015 were also analyzed. Immunohistochemical analysis was performed in the clini-

\section{KARGER}

E-Mail karger@karger.com

www.karger.com/oop
(C) 2015 S. Karger AG, Base

2296-4681/15/0022-0071\$39.50/0
Dr. Charles G. Eberhart

Department of Pathology, The Johns Hopkins University School of Medicine 720 Rutland Ave, Ross Building 558

Baltimore, MD 21205 (USA)

E-Mail ceberha@jhmi.edu 
Table 1. Immunohistochemical findings for each case

\begin{tabular}{lllll}
\hline $\begin{array}{l}\text { Patient } \\
\text { No. }\end{array}$ & $\begin{array}{l}\mathrm{p} 16 \\
\text { intraepithelial }\end{array}$ & $\begin{array}{l}\mathrm{p} 16 \\
\text { subepithelial }\end{array}$ & $\begin{array}{l}\mathrm{p} 53 \\
\text { intraepithelial }\end{array}$ & $\begin{array}{l}\mathrm{p} 53 \\
\text { subepithelial }\end{array}$ \\
\hline 1 & 2 & 2 & 3 & 3 \\
2 & 3 & 3 & 3 & 3 \\
3 & 2 & 2 & 1 & NTA \\
4 & 3 & 3 & 2 & NTA \\
5 & 3 & 3 & 3 & NTA \\
$5^{1}$ & 2 & 2 & 3 & 3 \\
6 & 3 & 3 & 3 & 3 \\
7 & 3 & 3 & 3 & 3 \\
8 & 3 & 3 & 0 & 0 \\
9 & 3 & 2 & 3 & 3 \\
10 & 3 & 3 & 3 & 3 \\
11 & 2 & 2 & 2 & 1 \\
12 & 3 & 3 & 0 & 1 \\
13 & 3 & 2 & 1 & 0 \\
14 & 3 & $\mathrm{~N}$ & 0 & $\mathrm{~N}$ \\
15 & 3 & 2 & 0 & NTA \\
$15^{1}$ & 3 & 3 & 0 & 0 \\
16 & 0 & 2 & 3 & 3 \\
17 & 1 & 1 & 1 & 3 \\
18 & 3 & 3 & 3 & 3 \\
$18^{1}$ & 3 & 3 & 3 & 3 \\
19 & 3 & $\mathrm{~N}$ & 0 & N \\
20 & 3 & 3 & 0 & 0 \\
$20^{1}$ & 3 & 3 & 0 & 0 \\
21 & 3 & 3 & 3 & \\
& & 3 & & \\
& 3 & 3 & 1 & 3 \\
\hline
\end{tabular}

NTA = No remaining tumor available in the block for staining in this region; $\mathrm{N}=$ no subepithelial mass identified.

${ }^{1}$ Recurrent tumor.

cal laboratory using 5- $\mu \mathrm{m}$ sections. A Leica Bond Max autostainer (Leica Microsystem, Bannockburn, Ill., USA) was used for p16 (Cintec, $1 \mu \mathrm{g} / \mathrm{ml}$ ) and a Ventana XT autostainer (Ventana Medical Systems, Tucson, Ariz., USA) for p53 (Ventana Medical Systems, $2.5 \mu \mathrm{g} / \mathrm{ml}$ ). Specimens were scored as having no (0), weak (1), moderate (2) or strong (3) immunoreactivity in $>50 \%$ of tumor cells.

\section{Results}

The 21 patients with periocular SC included 7 males and 14 females, ranging in age from 27 to 88 years (mean age: 72$) ; 18$ of the patients were Caucasian, 2 were Asian, and 1 was Black. All of the cases represented moderately to poorly differentiated tumors, with a few showing small clusters of better differentiated cells. In general, p16 protein was detected in both the cytoplasm and the nucleus of tumor cells, with relatively little immunoreactivity not- ed in nonneoplastic stromal elements. p53 was predominantly nuclear and was also largely restricted to tumor cells. The intensity of staining for both proteins was relatively constant in all neoplastic cells for a given case within subepithelial or intraepithelial sites and was not associated with differentiation status. Examples of various staining levels are shown in figure 1 , and the immunohistochemical findings for each case are reported in table 1.

Expression of p16 protein was examined in a total of 23 subepithelial SC, with $100 \%$ of these staining, including 22 with moderate to strong expression and only 1 showing weak immunoreactivity. An example of strong subepithelial p16 staining is shown in figure $1 \mathrm{~b}$, while weak staining is present in figure 1e. Of the 4 patients for whom primary and recurrent lesions were available, p16 expression remained strong or moderate in both lesions.

We also examined p53, but in cases No. 3-5 and 15, the subepithelial tumor was no longer present when this analysis was performed. Of the 19 lesions successfully evaluated, 12 (63\%) showed moderate or strong immunoreactivity, 2 (11\%) weak immunoreactivity and 5 (26\%) no immunoreactivity.

We next sought to determine if these markers would also highlight spreading tumor cells by examining intraepithelial disease in the cases discussed above, as well as an additional 2 tumors for which no subepithelial mass was identified. p16 expression was detected in intraepithelial tumor cells in 24 of the 25 cases (96\%), with only 1 case showing weak immunoreactivity. Intraepithelial p53 was present in 17 of 25 tumors (68\%), but was weak in 3 cases. As was true in the subepithelial neoplasm, intraepithelial expression of both p16 and p53 was similar or identical in primary and recurrent lesions and not associated with differentiation. However, while the expression remained stable over time, it did occasionally vary between the intraepithelial and subepithelial sites. No p16 was detected in intraepithelial tumor cells in case No. 16, while moderate staining was seen in the subepithelial lesion. For p53, case No. 12 showed weak staining in the main tumor mass but no immunoreactivity in the in-

Fig. 1. p16 and p53 immunoreactivity in periocular SC. a-c Subepithelial SC (case No. 8) with strong p16 immunoreactivity but no p53 staining (original magnification $\times 100$ ). $\mathbf{d}-\mathbf{f}$ Intraepithelial SC of the eyelid (case No. 17) with weak and strong p16 and p53 immunoreactivity, respectively (original magnification $\times 40$ ). $\mathbf{g - i}$ Intraepithelial SC (case No. 8) with strong p16 and negative p53 staining (original magnification $\times 200$ ). j-I Conjunctival intraepithelial SC (case No. 10) with strong p16 and p53 staining (original magnification $\times 200)$.

(For figure see next page.)
Ocul Oncol Pathol 2016;2:71-75 DOI: $10.1159 / 000439308$
Bell/Singh/Rajan KD/Eberhart 

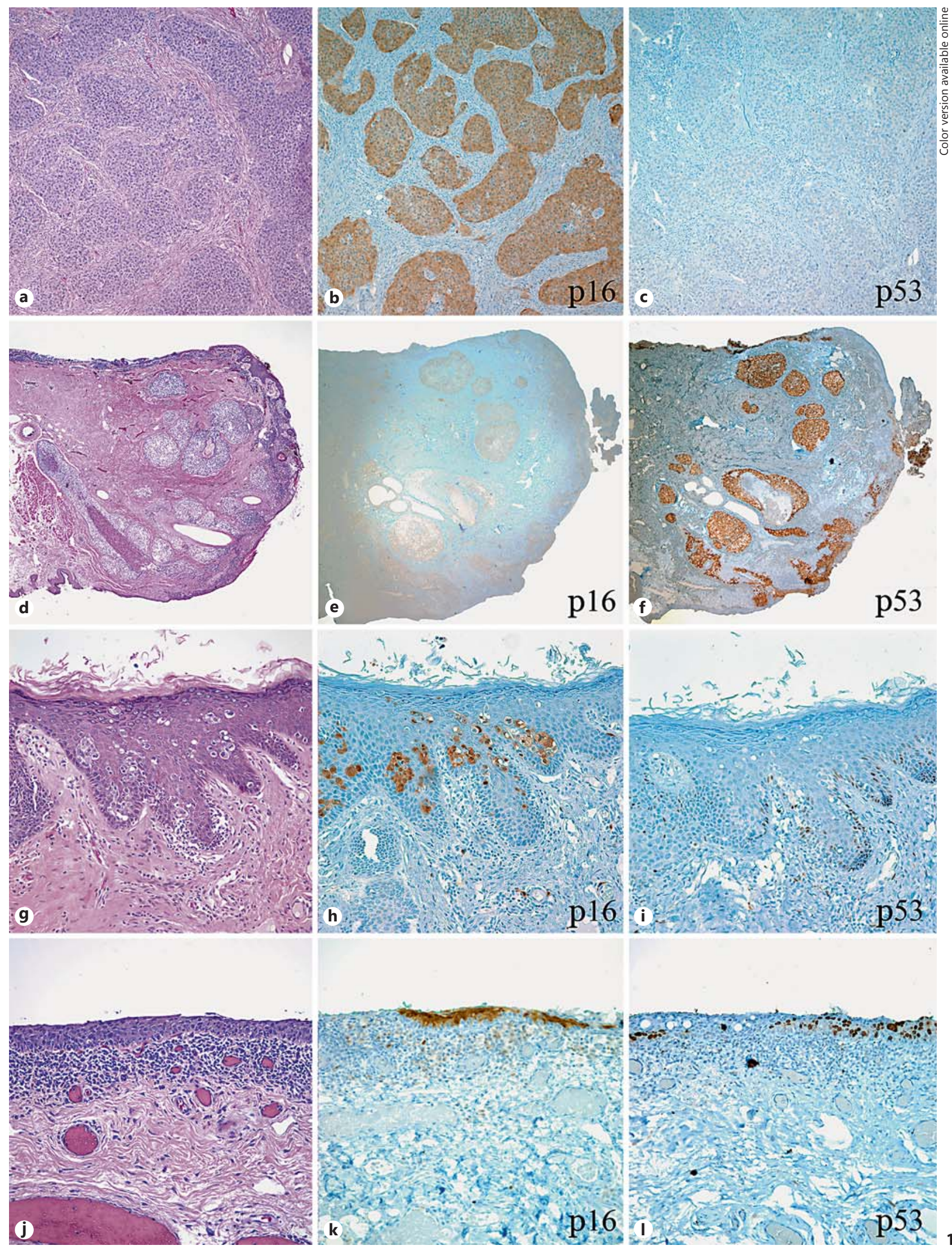
traepithelial disease, while the reverse was true in case No. 13. Scattered cases also showed changes from weak to moderate, or moderate to strong, between sites for both p16 and p53.

We additionally examined 3 consecutive cases of conjunctival intraepithelial neoplasia, including 1 which contained a focus of carcinoma in situ, as these can sometimes be difficult to distinguish from SC. In all 3 cases (100\%), p53 and p16 showed strong immunoreactivity.

\section{Discussion}

We identified p 16 and p53 as relatively robust markers of periocular SC, which can be used to facilitate the identification of tumor cells in the epithelium. While both were expressed in the majority of cases, approximately one quarter did not express $\mathrm{p} 53$ within intraepithelial tumor cells, and a single intraepithelial lesion was negative for p16. Our findings are largely concordant with prior publications, although earlier studies were smaller and did not specifically examine or report on intraepithelial tumor cells. With respect to p53, immunoreactivity has been reported in 8/15 SC cases (53\%) [4], 17/17 cases (100\%) [5], 22/42 cases (52\%) [6], 4/10 cases (40\%) [7] and $4 / 8$ cases (50\%) [8]. The combined incidence of $\mathrm{p} 53$ expression in these prior studies $(55 / 92 ; 60 \%)$ is relatively similar to the $63 \%$ with moderate or strong immunoreactivity which we identified in the main tumor masses.

With respect to p16, Kim et al. [7] examined 43 cases of eyelid SC and found high expression of p16 in 34 cases (79\%), with little expression in normal sebaceous glands. Another group reported overexpression of this protein in 10 of 14 cases $(71 \%)$ and noted that this was higher than in other types of eyelid tumors [9]. In contrast, Liau et al. [10] found diffuse and strong p16 expression in only 1 of 24 periocular carcinoma cases (4\%). They do not show an example of what they considered positive or negative p16 immunostaining, and it is unclear why the results of this group differ from ours and those listed above, although the fact that they score only nuclear protein may have played a role.

Several of these groups also addressed the potential cause of p53 and p16 expression in SC. Kiyosaki et al. [4] in Japan reported inactivating p53 mutations in 10 of 15 cases. A study in the United States found p53 mutations in $50 \%$ of 14 cases examined [11]. Although nuclear overexpression is not entirely specific to p53 mutations, intense nuclear immunoreactivity does correlate with signaling pathway dysregulation [12]. In carcinomas at oth- er sites, p16 expression is often used as a surrogate marker of human papilloma virus (HPV) infection. However, no HPV was detected in SC in the two studies which sought to correlate it with p16 immunoreactivity $[9,10]$.

Other malignancies or precancerous lesions in this region, such as conjunctival intraepithelial neoplasia, have also been shown to be immunoreacitive for these markers. Auw-Haedrich et al. [13] reported significantly increased expression of p16 and Ki67 in 100\% of 12 cases of conjunctival intraepithelial neoplasia, without correlation to differentiation grade or HPV infection. Another group examined both p16 and p53 immunoreactivity in 13 consecutive patients with conjunctival squamous cell carcinoma and found that all were positive for both of these markers [14]. Finally, we examined p16 and p53 in 3 consecutive conjunctival dysplasia and carcinoma in situ cases, all of which showed strong nuclear reactivity for p53 and both strong nuclear and cytoplasmic reactivity for $\mathrm{p} 16$. These combined data suggest that neither p16 nor p53 can be used to distinguish SC from other conjunctival carcinomas.

In summary, our data suggest that p16 and p53 immunohistochemistry can be useful in highlighting intraepithelial SC, but if only one stain can be ordered, p16 will be more effective; however, while searching for intraepithelial SC cells when the expression status of the primary lesion is not known, using a combination of both p53 and p16 gives the greatest chance of highlighting neoplastic cells. It should be emphasized that malignancies in the eyelid other than SC can express p16 and p53, and it is not thought that they can clearly discriminate sebaceous tumors from other neoplasms at this site $[13,14]$. In addition, both p53 and p16 expression can sometimes be seen in nonneoplastic cells, necessitating the correlation of immunoreactivity with enlarged, pleomorphic nuclei and/ or vacuolated cytoplasm before determining that the stains are highlighting SC. Nevertheless, in our experience, these stains can be quite helpful in the evaluation of SC spread around the eye.

\section{Statement of Ethics}

The subjects in this study gave informed consent, and the study protocol has been approved by the Institutional Review Board.

\section{Disclosure Statement}

The authors disclose that no sponsorship or funding arrangements relating to their research pose a conflict of interest.
Bell/Singh/Rajan KD/Eberhart 


\section{References}

1 Doxanas MT, Green WR: Sebaceous gland carcinoma. Review of 40 cases. Arch Ophthalmol 1984;102:245-249.

2 Kwitko ML, Boniuk M, Zimmerman LE: Eyelid tumors with reference to lesions confused with squamous cell carcinoma. 1. Incidence and errors in diagnosis. Arch Ophthalmol 1963;69:693-697.

3 Welch RB, Duke JR: Lesions of the lids; a statistical note. Am J Ophthalmol 1958;45:415426.

4 Kiyosaki K, Nakada C, Hijiya N, Tsukamoto Y, Matsuura K, Nakatsuka K, Daa T, Yokoyama S, Imaizumi M, Moriyama M: Analysis of p53 mutations and the expression of p53 and p21WAF1/CIP1 protein in 15 cases of sebaceous carcinoma of the eyelid. Invest Ophthalmol Vis Sci 2010;51:7-11.

5 Jakobiec FA, Mendoza PR: Eyelid sebaceous carcinoma: clinicopathologic and multiparametric immunohistochemical analysis that includes adipophilin. Am J Ophthalmol 2014; 157:186-208.e2.
6 Shalin SC, Sakharpe A, Lyle S, Lev D, Calonje E, Lazar AJ: p53 staining correlates with tumor type and location in sebaceous neoplasms. Am J Dermatopathol 2012;34:129135.

7 Kim N, Kim JE, Choung HK, Lee MJ, Khwarg SI: Expression of cell cycle regulatory proteins in eyelid sebaceous gland carcinoma: low p27 expression predicts poor prognosis. Exp Eye Res 2014;118:46-52.

8 Cabral ES, Auerbach A, Killian JK, Barrett TL, Cassarino DS: Distinction of benign sebaceous proliferations from sebaceous carcinomas by immunohistochemistry. Am J Dermatopathol 2006;28:465-471.

9 Kwon MJ, Shin HS, Nam ES, Cho SJ, Lee MJ, Lee S, Park HR: Comparison of HER2 gene amplification and KRAS alteration in eyelid sebaceous carcinomas with that in other eyelid tumors. Pathol Res Pract 2015;211:349355.

10 Liau JY, Liao SL, Hsiao CH, Lin MC, Chang HC, Kuo KT: Hypermethylation of the CDKN2A gene promoter is a frequent epigenetic change in periocular sebaceous carcinoma and is associated with younger patient age. Hum Pathol 2014;45:533-539
11 Hussain RM, Matthews JL, Dubovy SR, Thompson JM, Wang G: UV-independent p53 mutations in sebaceous carcinoma of the eyelid. Ophthal Plast Reconstr Surg 2014;30: 392-395.

12 Ren ZP, Pontén F, Nistér M, Pontén J: Two distinct p53 immunohistochemical patterns in human squamous-cell skin cancer, precursors and normal epidermis. Int J Cancer 1996; 69:174-179.

13 Auw-Haedrich C, Martin G, Spelsberg H, Sundmacher R, Freudenberg N, Maier P, Reinhard T: Expression of p16 in conjunctival intraepithelial neoplasia does not correlate with HPV-infection. Open Ophthalmol J 2008;2:48-56.

14 Jung SM, Lin HC, Chu PH, Wu HH, Shiu TF, Huang SL, Lai CH: Expression of cell cycleregulatory proteins, MIB-1, p16, p53, and p63, in squamous cell carcinoma of conjunctiva: not associated with human papillomavirus infection. Virchows Arch 2006;448:301305 